\title{
DYNAMICS OF DECADAL CLIMATE VARIABILITY AND IMPLICATIONS FOR ITS PREDICTION
}

\author{
Mojib Latif $^{(1)}$, Tom Delworth ${ }^{(2)}$, Dietmar Dommenget ${ }^{(1)}$, Helge Drange $^{(3)}$, Wilco Hazeleger $^{(4)}$, Jim HurrelI $^{(5)}$, \\ Noel Keenlyside ${ }^{(1)}$, Jerry Meehl ${ }^{(5)}$, and Rowan Sutton ${ }^{(6)}$ \\ (1) Leibniz-Institut für Meereswissenschaften/Leibniz Institute of Marine Sciences, IFM-GEOMAR (Research Center for \\ Marine Geosciences), Dienstgebäude Westufer Düsternbrooker Weg 20, D-24105 Kiel, Germany, \\ Email:mlatif@ifm-geomar.de; ddommenget@ifm-geomar.de; nkeenlyside@ifm-geomar.de \\ ${ }^{(2)}$ Geophysical Fluid Dynamics Laboratory (GFDL), Princeton University, Forrestal Campus, 201 Forrestal Road, \\ Princeton, NJ08540-6649, USA, Email: tom.delworth@noaa.gov \\ (3) Department of Geophysics, University of Bergen, Allegt. 70, 5007 Bergen, Norway, Email: helge.drange@gfi.uib.no

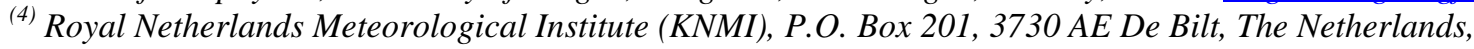 \\ Email: Wilco.Hazeleger@knmi.nl \\ ${ }^{(5)}$ National Center for Atmospheric Research (NCAR), 1850 Table Mesa Drive, Boulder, CO, 80305, USA, Email: \\ jhurrell@ucar.edu; meehl@ncar.ucar.edu \\ (6) Climate Division of the UK National Centre for Atmospheric Science (NCAS), Department of Meteorology, \\ University of Reading, PO Box 243, Earley Gate, Reading RG6 6BB, U.K., Email: R. Sutton@rdg.ac.uk
}

\begin{abstract}
The temperature record of the last 150 years is characterized by a long-term warming trend, with strong multidecadal variability superimposed. The multidecadal variability is also seen in other (societal important) parameters such as Sahel rainfall or Atlantic hurricane activity. The existence of the multidecadal variability makes climate change detection a challenge, since Global Warming evolves on a similar timescale. The ongoing discussion about a potential anthropogenic signal in the Atlantic hurricane activity is an example. A lot of work was devoted during the last years to understand the dynamics of the multidecadal variability, and external as well as internal mechanisms were proposed. This White Paper focuses on the internal mechanisms relevant to the Atlantic Multidecadal Oscillation/Variability (AMO/V) and the Pacific Decadal Oscillation/Variability $(\mathrm{PDO} / \mathrm{V})$. Specific attention is given to the role of the Meridional Overturning Circulation (MOC) in the Atlantic. The implications for decadal predictability and prediction are discussed.
\end{abstract}

\section{INTRODUCTION}

Climate variability can be either generated internally by interactions within or between the individual climate subcomponents (e.g., atmosphere, ocean, and sea ice) or externally by e.g. volcanic eruptions, variations in the solar insolation at the top of the atmosphere, or changed atmospheric greenhouse gas concentrations in response to anthropogenic emissions. Examples of internal variations are the North Atlantic Oscillation (NAO), the El Niño/Southern Oscillation (ENSO), the Pacific Decadal Variability (PDV), or the Atlantic Multidecadal Variability (AMV). We present in Fig. 1 indices derived from observations to visualize the decadal variability in selected variables and regions. The North Atlantic Sector is one region of strong multidecadal variability, and multidecadal variability can be readily seen, for instance, in European surface air temperature (SAT), Sahel rainfall, and Atlantic Hurricane activity. All three indices are highly correlated with the fluctuations in North Atlantic sea surface temperature (SST) on decadal timescales. Similar behaviour is seen in the North Pacific; the correspondence between SAT in the Southwest United States, the region most strongly affected by the PDV, and North Pacific SST (as given by the PDO index), however, is obvious but less significant.

Uncertainty in climate change projections for the $21_{\mathrm{st}}$ century arises from three distinct sources: internal variability, model errors and scenario uncertainty. Using data from a suite of climate models [22] separate and quantify these sources (Fig. 2). For lead times of the next few decades, the dominant contributions are internal variability and model uncertainty. The importance of internal variability generally increases at shorter time and space scales. ENSO, for instance, is one of the major factors affecting inter-annual variability, even on a global scale. The analyses of [22] suggest that for decadal timescales and regional spatial scales $(\sim 2000 \mathrm{~km})$, model uncertainty is of greater importance than internal variability. Both the contributions to prediction uncertainty from internal variability and, especially, model uncertainty are potentially reducible through progress in climate research. Model biases are still rather large and model improvement will most likely lead to higher prediction skill, an experience made in numerical weather forecasting (NWP) and seasonal forecasting. Another lesson from NWP and seasonal forecasting is that predictions considerably benefit from better knowledge of the initial conditions and initialization methods. 

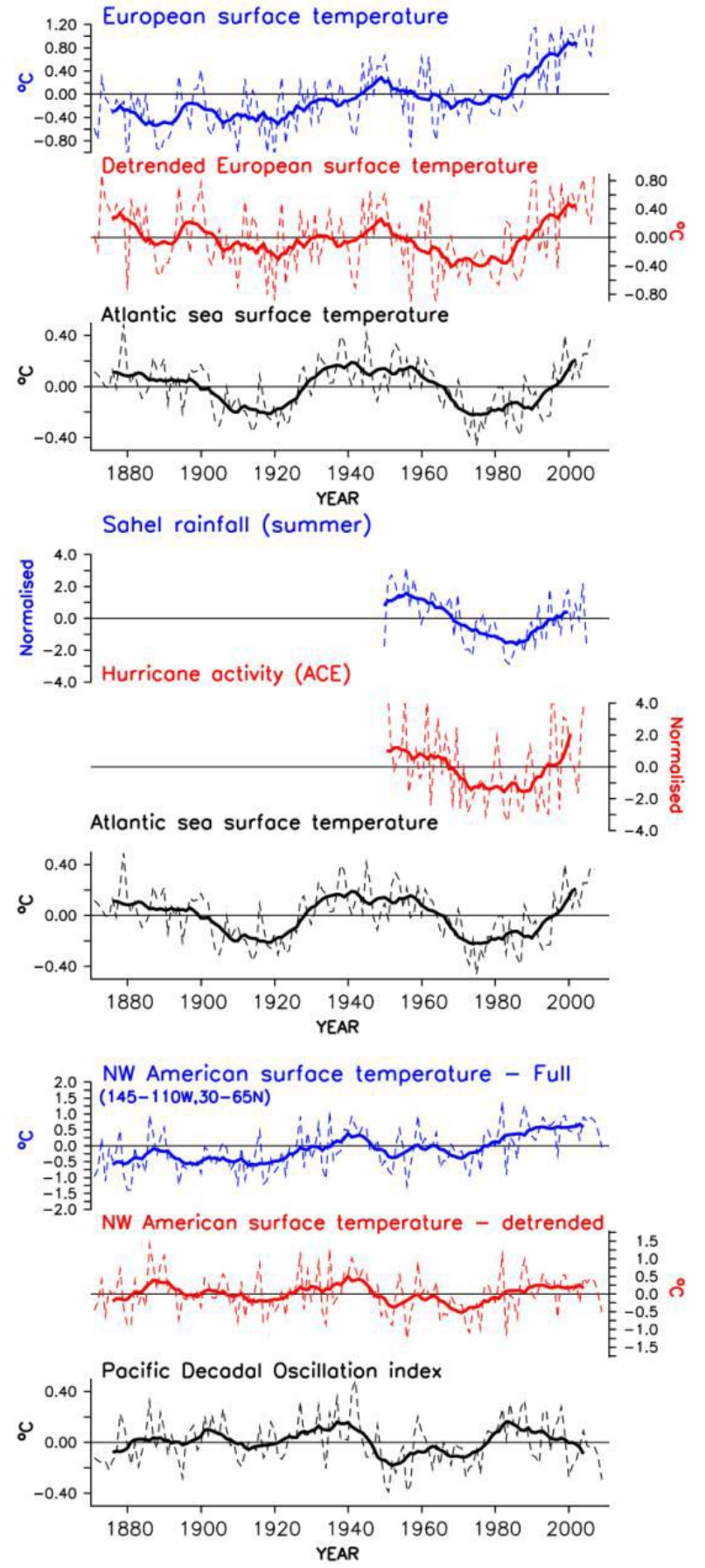

Figure 1. From top to bottom: Annual mean European SAT $\left(5^{\circ} \mathrm{W}-10^{\circ} \mathrm{E}, 35-60^{\circ} \mathrm{N}\right)$, linearly de-trended annual mean

European SAT, linearly de-trended North Atlantic SST (0$\left.60^{\circ} \mathrm{N}\right)$, summer Sahel rainfall, Atlantic hurricane activity (ACE (Accumulated Cyclone Energy) index), and North Atlantic SST repeated from above. The bottom three panels show northwestern United States SAT, the linearly de-trended version, and the PDO index. All time series are deviations from the long-term mean. All temperature time series are in units of $\left[{ }^{\circ} \mathrm{C}\right]$. The Sahel rainfall and the ACE index were normalized with the long-term standard deviation.

In this White Paper, we focus on the internal decadal variability and its dynamics. A large body of literature exists on these dynamics and we try to summarize this knowledge in a concise way. Reference [2] concluded from his early analysis of the observations in the midlatitudinal Atlantic region that the atmosphere drives the ocean at interannual time scales, while at the decadal to multidecadal time scales it is the ocean dynamics that matters. Many subsequent observational and modelling studies agree basically with this view (e.g. [8] and [28]; and references therein), so the predictability potential in the Atlantic Sector is probably large at the decadal to multidecadal timescales [32]. Although the mechanisms behind the decadal to multidecadal variability in the Atlantic Sector are still controversial, there is some consensus that some of the longer-term multidecadal variability is driven by variations in the thermohaline circulation (THC). In the North Pacific, a strong overturning circulation does not exist, and variations in the winddriven circulation are the most likely candidate for the generation of decadal to multidecadal variability (e.g. [28], [43] and [29]). Rossby wave propagation is important in this context.

Here we concentrate on the North Atlantic and the North Pacific Sectors, two regions of considerable potential decadal predictability (Fig. 3). We note, however, that other regions such as the Southern Ocean also exhibit relatively high predictability potentials. In Sect. 2, we discuss some aspects of potential decadal predictability. Section 3 provides a conceptual description of the different possible mechanisms that can lead to decadal variability. Again, we consider only variability that is driven internally and involves the interaction between the ocean-sea ice system and the atmosphere. This type of variability must be treated within a stochastic framework. We do not consider chaotic variability originating in either only the atmosphere or the ocean-sea ice system. The main conclusions are drawn in Sect. 4.

\section{DECADAL PREDICTABILITY}

Climate prediction has been mostly considered on two different time scales: seasonal and centennial. Seasonal prediction is primarily an initial value problem, i.e. the evolution of the system depends on the initial state.

Whereas centennial-scale prediction is normally considered a boundary value problem (e.g. [38]), i.e. the evolution of climate depends on external changes in radiative forcing, such as anthropogenic changes in atmospheric composition or solar forcing ([25]). What class of problem is decadal prediction: initial value or boundary value? As suggested by observations and models decadal climate variations - global and regional - may arise from internal modes of the climate system and be potentially predictable (i.e. an initial value problem). On the other hand, projections of future climate indicate a rise in global mean temperature of 
between 2 and $4^{\circ} \mathrm{C}$ by 2100 , dependant on emission scenario and model. This translates to an average rise in global mean temperature of order $0.3^{\circ} \mathrm{C}$ per decade. This is large compared, for instance, with the observed increase of about $0.7^{\circ} \mathrm{C}$ during the last century, and

A

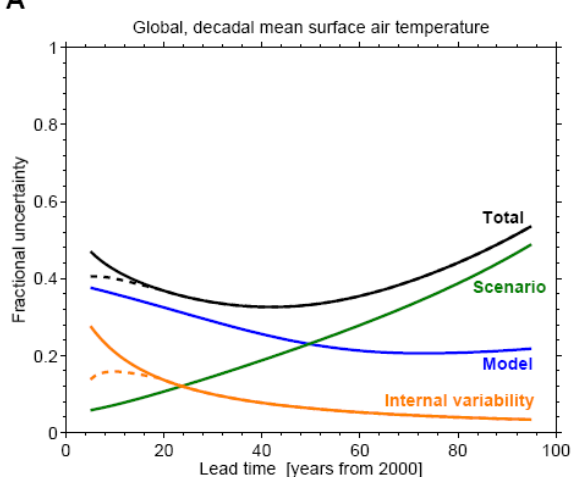

C

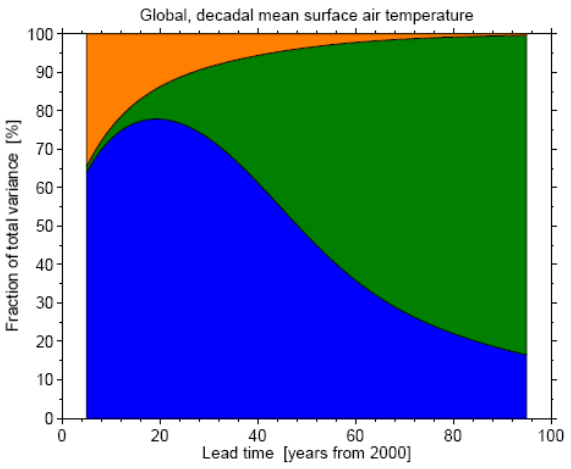

argues that decadal prediction is also a boundary value problem. Thus, the prediction of the climate over the next few decades poses a joint initial/boundary value problem.

B

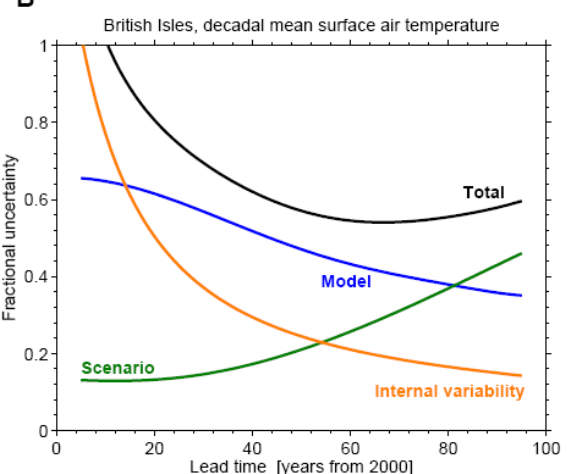

D

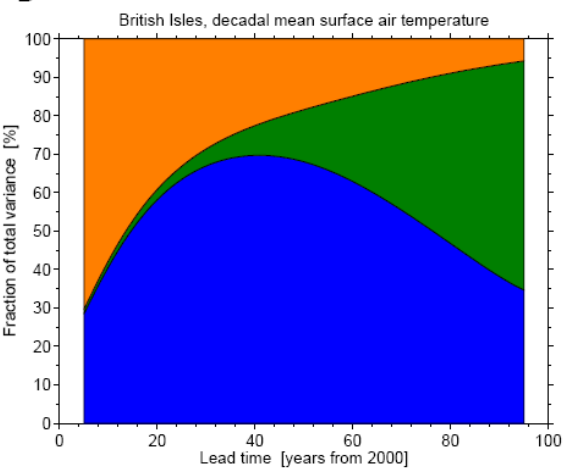

Figure 2. The relative importance of each source of uncertainty in decadal mean surface temperature projections is shown by the fractional uncertainty (the $90 \%$ confidence level divided by the mean prediction), for (A) global mean, relative to the warming from the 1971-2000 mean, and $(\boldsymbol{B})$ British Isles mean, relative to the warming from the 1971-

2000 mean. Internal variability grows in importance for the smaller region. Scenario uncertainty only becomes important at multi-decadal lead times. The dashed lines in $(\boldsymbol{A})$ indicate reductions in internal variability, and hence total uncertainty, that may be possible through proper initialisation of the predictions through assimilation of ocean observations (Smith et al., 2007). The fraction of total variance in decadal mean surface air temperature predictions explained by the three components of total uncertainty is shown for, $(\boldsymbol{C})$ a global mean, $(\boldsymbol{D})$ a British Isles mean. Green regions represent scenario uncertainty, blue regions represent model uncertainty and orange regions represent the internal variability component. As the size of the region is reduced, the relative importance of internal variability increases. From [22].

While the predictability of internal fluctuations on seasonal timescales has been intensively studied for more than twenty years, decadal predictability has been systematically investigated for only a few years. One reason is the much longer timescale, which requires rather long model integrations and which is therefore closely related to the availability of large computer resources. One distinguishes between potential (diagnostic) and classical (prognostic) predictability studies. Potential predictability (e.g. [3]) attempts to quantify the fraction of long-term variability that may be distinguished from the internally generated natural variability, which is not predictable on long time scales and considered as "noise". The long-term variability "signal" that rises above this noise is deemed to arise from processes operating in the physical system that are assumed to be, at least potentially, predictable. Decadal potential predictability is simply defined as the ratio of the variance on the decadal time scales to the total variance. Classical predictability studies consist of performing ensemble experiments with a single coupled model perturbing the initial conditions ([16], [17], [18], [4], [5] and [40]). The predictability of a variable is given by the ratio of the actual signal variance to the ensemble variance. This method provides in most cases an upper limit of predictability 
since they assume a perfect model and, very often, near-perfect initial conditions. A third method compares the variability simulated with and without active ocean dynamics. Those regions in which ocean dynamics are important in generating the decadal variability are believed to be regions of high decadal predictability potential ([39]).

All three types of studies yield similar results for decadal predictability ([32]). In contrast to seasonal to interannual predictability potential decadal predictability is found predominately over the mid to high-latitude oceans ([3]). The potential decadal predictability decreases with increasing timescale but appreciable values exist up to multidecadal timescales, especially for the North Atlantic and the Southern Ocean (Fig. 3). In the North Pacific, the decadal predictability potential is considerably smaller, but probably still useful. It should be mentioned that these results hold only for the internal variability. Results obtained by including externally driven variability such as that related to an increase in atmospheric greenhouse gas concentrations yield rather different results ([22]). This can be easily understood by considering, for instance, the North Atlantic. MOC (Meridional Overturning Circulation)- related decadal variations are strong in this region and appear to be predictable. In contrast, the expected anthropogenic weakening of the MOC may not be well detectable for many decades due to the existence of the strong internal variability. So, predictability will critically depend on the lead time. On short lead times of a decade, the internal variability may dominate. On long lead times of a century, the weakening in response to changing boundary conditions may prevail.

10-year means

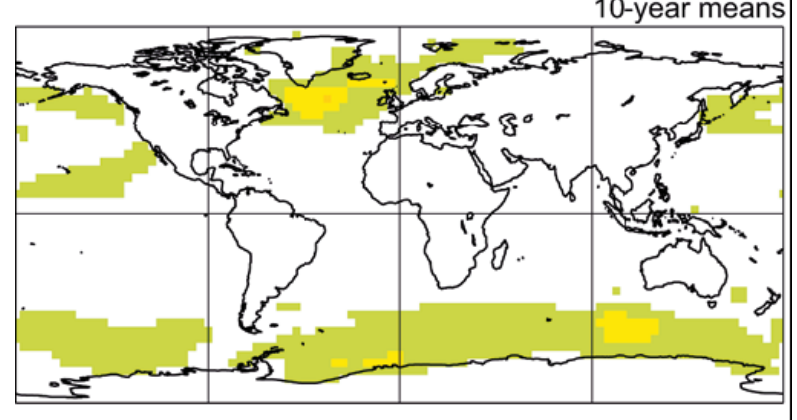

Figure 3. Potential decadal predictability considering $25-$ year means obtained from the ensemble of coupled oceanatmosphere models. See text for details. From [3].

\section{MECHANISMS FOR DECADAL VARIABILITY}

The climate system displays variability over a broad range of timescales, from monthly to millennial and to even longer timescales. It is impossible to describe the full range of climate variability deterministically with one model, since the governing equations are too complicated so that an analytical solution is not known.
A numerical solution of the complete equations is not feasible, because the necessary computer resources are not available, and will not be available over the next years. The climate system is comprised of components with very different internal timescales. Weather phenomena, for instance, have typical lifetimes of hours or days, while the deep ocean needs many centuries to adjust to changes in surface boundary conditions. Reference [21] introduced an approach to modelling the effect of the fast variables on the slow in analogy to Brownian motion. He suggested treating the former not as deterministic variables, but as stochastic variables, so that the slow variables evolve following dynamical equations with stochastic forcing. The chaotic components of the system often have welldefined statistical properties and these can be built into approximate stochastic representations of the highfrequency variability. The resulting models for the slow variables are referred to collectively as stochastic climate models, although the precise timescale considered slow may vary greatly from model to model. We describe in the following the different models which were suggested for the generation of the internally driven decadal variability.

\subsection{The zero-order stochastic climate model}

We consider in the following discussion the atmosphere as the fast and the ocean-sea ice system as the slow component. In the simplest case, the atmosphere is treated as a white noise process, i.e. the spectrum of the atmospheric forcing agents such as the air-sea heat flux is white, i.e. does not have a variation with frequency. Furthermore, we assume first a local model in which the atmospheric forcing at one location drives only changes in the ocean-sea ice system at this very point; and neither the atmosphere nor the oceanice system exhibit spatial coherence. The resulting spectrum of an ocean variable say sea surface temperature (SST) is red, which means that the power increases with timescale. To avoid a singularity at zero frequency a damping was introduced by [21]. Reference [14] and [20] have shown that such a local model can indeed explain observed SST and salinity variability in parts of the Mid- Latitudes, away from coasts and fronts, and that climate models do reproduce this behaviour. In regions where meso-scale eddies or advection is important, the simple stochastic models fail too. Nevertheless, the simple local model demonstrates that decadal variability in the ocean-sea ice system can be easily be generated by the integration of atmospheric weather noise. This model can be considered as a null hypothesis for the generation of decadal variability.

\subsection{Stochastic models with mean advection}

Atmospheric variability on timescales of a month or longer is dominated by a small number of large-scale 
spatial patterns, whose time evolution has a significant stochastic component. One prominent example is the North Atlantic Oscillation (NAO, [24]), and we shall discuss the role of the NAO in driving variations in the thermohaline circulation (THC) below. One may expect the atmospheric patterns to play an important role in ocean-atmosphere interaction. Advection in the ocean-sea ice system plays an important role in this coupling. Reference [35] has fitted a stochastic model incorporating horizontal transport to observed polar sea ice variability. Reference [12] describe the use of a local stochastic model, including the effects of advection by the observed mean current, to predict the statistical characteristics of observed SST anomalies in the North Pacific on timescales of several months. They find that mean advection has only a small effect in general, although in regions of large currents, the advection effects were important at lower frequencies. Reference [23] has fitted a more general nonlocal stochastic model, incorporating advection and diffusion, to observed SST anomalies over the same region.

A simple one-dimensional stochastic model of the interaction between spatially coherent atmospheric forcing patterns and an advective ocean was developed by [41]. Their model equations are simple enough and allow analytical treatment. A slow-shallow regime where local damping effects dominate and a fast-deep regime where nonlocal advective effects dominate were found. An interesting feature of the fast-deep regime is that the ocean-atmosphere system shows preferred timescales, although there is no underlying oscillatory mechanism, neither in the ocean nor in the atmosphere. The existence of the preferred timescale in the ocean does not depend on the existence of an atmospheric response to SST anomalies. It is determined by the advective velocity scale associated with the upper ocean and the length scale associated with lowfrequency atmospheric variability. This mechanism is often referred to as "spatial resonance" or "optimal forcing". For the extra-tropical North Atlantic basin, this timescale would be of the order of a decade. Interestingly, [9], [46], and [1] find such a decadal timescale in surface observations of the North Atlantic. However, the studies differ in the derived propagation characteristics. The stochastic-advective mechanism may also underlie the Antarctic Circumpolar Wave (ACW, e. g. [48], as shown in the model study of [50] who drove an ocean-sea ice general circulation model by spatially coherent but temporally white forcing. The analyzed model experiment is also described below, when we discuss the variability of the THC.

\subsection{Stochastic wind stress forcing of a dynamical ocean}

We have considered so far no varying ocean dynamics and only thermohaline forcing, i.e. heat and freshwater forcing. Reference [13] used a simple linear model to estimate the dynamical response of the extra-tropical ocean to stochastic wind stress forcing with a white frequency spectrum. The barotropic fields are governed by a time-dependent Sverdrup balance, the baroclinic ones by the long Rossby wave equation. At each frequency, the baroclinic response consists of a forced response plus a Rossby wave generated at the eastern boundary. For zonally independent forcing, the response propagates westward at twice the Rossby phase speed. The model predicts the shape and level of the frequency spectra of the oceanic pressure field and their variation with longitude and latitude. The baroclinic response is spread over a continuum of frequencies, with a dominant timescale determined by the time it takes a long baroclinic Rossby wave to propagate across the basin and thus increases with the basin width. The baroclinic predictions for a white wind stress curl spectrum are broadly consistent with the frequency spectrum of sea level changes and temperature fluctuations in the thermocline observed near Bermuda. Reference [44] found some evidence for the accumulation of stochastic atmospheric forcing along Rossby wave trajectories in the North Pacific. Stochastic wind stress forcing may thus explain a substantial part of the decadal variability of the oceanic gyres, especially in the North Pacific. The importance of stochastically driven Rossby waves was also described in [29] who studied the multidecadal variability in the North Pacific in a coupled oceanatmosphere general circulation model. His results suggest that the multidecadal variability can be partly explained by the dynamical ocean response to stochastic wind stress forcing. Superimposed on the red background variability, a multidecadal mode with a period of about $40 \mathrm{yr}$ is simulated which can be understood through the concept of spatial resonance between the ocean and the atmosphere, as described above. In summary, the bulk of the potential predictability found in the North Pacific (e.g. [3]) is probably related to the propagation of long baroclinic Rossby waves (e.g. [43]). The degree of air-sea coupling, however, needs to be considered in this context (e.g. [30]), as well as the role of remote forcing by the Tropics (e.g. [19] and [26]). 


\subsection{Hyper modes}

We describe now a case in which the atmosphere is no longer represented by a simple stochastic model but deterministically by an atmospheric general circulation model. The ocean is represented by a vertical column model that only includes vertical diffusion. Such a coupled model (AGCM-ML (Atmospheric General Circulation Model-Mixed-Layer Ocean) was studied, for instance, by [10] and displays many features described above. Since varying ocean dynamics are not considered, air-sea interactions are purely local. It is shown that some important aspects of the space-time structure of multidecadal sea surface temperature (SST) variability can be explained by such a model. Reference [10] formulate the concept of "Global Hyper Climate Modes", in which surface heat flux variability associated with regional atmospheric variability patterns is integrated by the large heat capacity of the extra-tropical oceans, leading to a continuous increase of SST variance towards longer timescales. Atmospheric teleconnections spread the extra-tropical signal to the tropical regions. Once SST anomalies have developed in the Tropics, global atmospheric teleconnections spread the signal around the world creating a global "hyper" climate mode. Estimates with a further reduced model suggest that hyper climate modes can vary on timescales longer than 1,000 years. The SST anomaly patterns simulated at multidecadal timescales in the model of [10] are remarkably similar to those derived from observations and from long control integrations with sophisticated coupled oceanatmosphere general circulation models (Fig. 4). The hyper mode mechanism could, for instance, underlie the Pacific Decadal Oscillation, whose structure is reasonably well reproduced in the [10] model at multidecadal timescales.

Ocean dynamics and large-scale ocean-atmosphere coupling may amplify the hyper modes, especially in the Tropics, and may influence the regional expression of the associated variability. Equatorial ocean dynamics such as those operating in ENSO, for instance, would enhance the variability in the eastern and central Equatorial Pacific. Such feedbacks would make the model certainly more realistic, but are not at the heart of the mechanism which produces the hyper modes.

\subsection{Stochastically driven variability of the thermohaline circulation}

We now discuss the decadal variability of the thermohaline circulation (THC). Competing mechanisms were proposed for the North Atlantic Meridional Overturning Circulation (MOC) variability. One idea is that multidecadal MOC variability is driven by the low-frequency portion of the spectrum of atmospheric flux forcing. Reference [36] describe results from a multi-millennial integration with the Hamburg Large-Scale Geostrophic (LSG) Ocean General Circulation Model which was driven by spatially correlated white-noise freshwater flux anomalies. In addition to the expected red-noise character of the oceanic response, the model simulated pronounced variability in a frequency band around 320 years in the Atlantic basin. This is due to the excitation of a damped oceanic eigenmode by the stochastic freshwater flux forcing.

The physics behind the variability involve a dipole-like salinity anomaly advected by and interacting with the mean THC. Reference [49] describes decadal variability with a timescale of the order of 10 to 40 years in the North Atlantic in the same experiment. It describes the generation of salinity anomalies in the Labrador Sea and the following discharge into the North Atlantic. The generation of the salinity anomalies is mainly due to an almost undisturbed local integration of the white noise freshwater fluxes. The timescale and damping term of the integration process are determined by the flushing time of the well-mixed upper layer. The decadal mode affects the MOC and represents a "discharge process" that depends nonlinearly on the modulated circulation structure rather than a regular linear oscillator.

Reference [7], investigating the multidecadal variability in the coupled model simulation of [8], also describe an internal ocean mode in their analysis of a series of coupled and uncoupled ocean model integrations. The multidecadal variability simulated in the model discussed in [8] involves interactions of the gyre and thermohaline circulations, in which the anomalous salt advection into the sinking region plays a crucial role in determining deep convection. [7] show that the multidecadal MOC fluctuations are driven by a spatial pattern of surface heat flux variations that bear a strong resemblance to the NAO. No conclusive evidence is found that the MOC variability is part of a dynamically coupled atmosphere-ocean mode in this particular model. Reference [15] interpreted the same coupled model simulation in terms of a stochastically forced four-box model of the MOC. The box model was placed in a linearly stable thermally dominant mean state under mixed boundary conditions ([45]). A linear stability analysis of this state reveals one damped oscillatory THC mode in addition to purely damped modes. Direct comparison of the variability in the box model and coupled ocean-atmosphere model reveals common qualitative aspects. Such a comparison supports the hypothesis that the coupled model's MOC variability can be described by the stochastic excitation of a linear damped oscillatory THC mode. 
a) ECHAM5-OZ EOF-1 (14\%) timescale: 1-5yrs

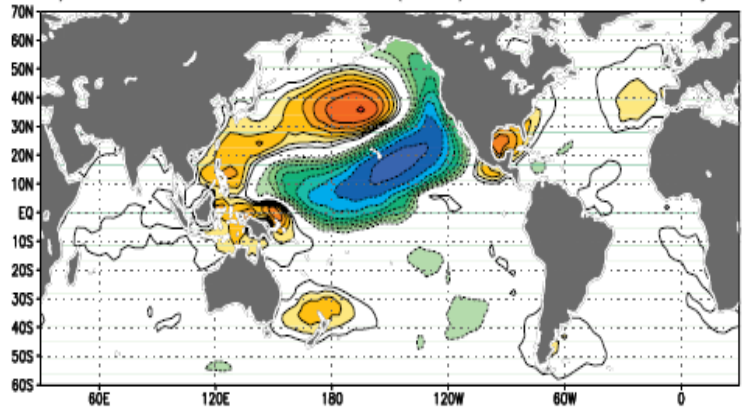

b) ECHAM5-OZ EOF-1 (18\%) timescale: 5-20yrs

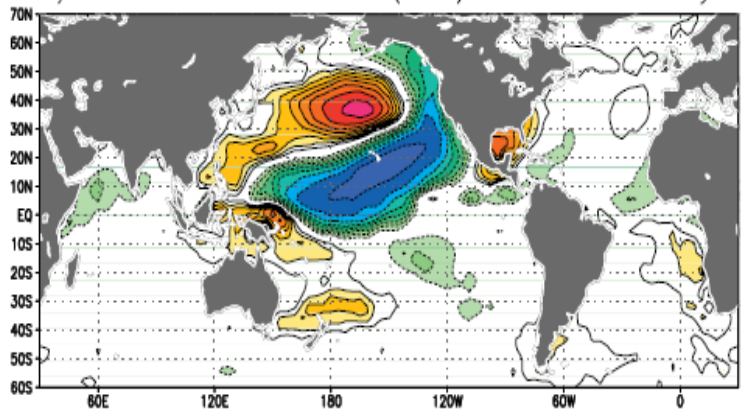

c) ECHAM5-OZ EOF-1 (29\%) timescale: >40yrs

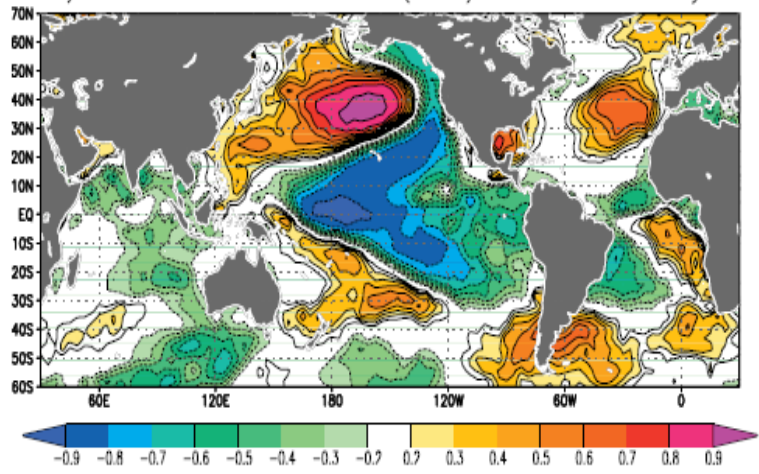

Figure 4. Correlation maps with the EOF-1 time series of the simple global climate model (AGCM-ML) at different timescales: a) timescales of 1-5 years, $b$ ) timescales of 5-41 years, c) timescales longer than 41 years. Filtering was performed by applying and/or subtracting running means. The hyper mode is fully developed at multidecadal timescales. From [10].

Coupled air-sea modes were also proposed as mechanisms for decadal variability. Reference [47] describes coupled variability with a $35-y r$ period in a multicentury integration of the ECHAM3/LSG climate model. An anomalously strong MOC drives positive SST anomalies in the North Atlantic. The atmospheric response to these involves a strengthened NAO, which leads to anomalously weak evaporation and Ekman transport off Newfoundland and in the Greenland Sea and the generation of negative sea surface salinity (SSS) anomalies. Reduced deep convection in the oceanic sinking regions and a subsequently weakened MOC eventually lead to the formation of negative SST anomalies.

Reference [11] describes results from a simple stochastic atmosphere model coupled to a realistic model of the North Atlantic Ocean. A north-south SST dipole, with its zero line centred along the sub-polar front, drives the atmosphere model, which in turn forces the ocean model by NAO-related surface fluxes. The model simulates a damped decadal oscillation. It consists of a fast wind-driven, positive feedback of the ocean and a delayed negative feedback orchestrated by shallow overturning circulation anomalies. The positive feedback turns out to be necessary to distinguish the coupled oscillation from that in a model without any feedback from the ocean to the atmosphere. Anomalous geostrophic advection appears to be important in sustaining the oscillation.

The uncertainties in the atmospheric response to midlatitude SST anomalies and thus the strength of air-sea coupling is still an open scientific question and explain some of the major differences between models. Recent studies suggest that the resolution (horizontal and vertical) of atmosphere models may not be sufficient to resolve phenomena such as variations in the position of the polar front ([37]). Furthermore, stratospheric and tropospheric variability are linked on seasonal time scales, as shown by observational and modelling studies (see e.g., [27] and references therein). It follows that low-frequency stratospheric change, of either natural or anthropogenic origin, can influence tropospheric circulation. This was recently highlighted in experiments that showed that the observed strengthening of the stratospheric jet from 1965-1995 could reproduce the observed changes in the NAO and North Atlantic Sector climate ([42]).

\section{CONCLUSIONS}

Decadal climate prediction is of socio-economic importance and has a potentially important role to play in policy making. In contrast to seasonal prediction and centennial climate projections, it is a joint initial value/boundary value problem. Thus, both accurate projections of changes in radiative forcing and initialisation of the climate state, particularly the ocean, are required. Although the first promising steps towards decadal prediction have been made, much more work is required. Most importantly, understanding of the mechanisms of decadal-tomultidecadal variability is lacking. The atmospheric response to mid-latitudinal SST anomalies, for instance, is still highly controversial and future research should treat this as a key topic. 
The decadal predictability potential is rather large in the North Atlantic Sector. Although the mechanisms behind the decadal to multidecadal variability in the North Atlantic Sector are still controversial, there is some consensus that some of the longer-term multidecadal variability is driven by variations in the thermohaline circulation. Analyses of ocean observations and model simulations by [33] suggest that there have been considerable changes in the thermohaline circulation during the last century. These changes are likely to be the result of natural multidecadal climate variability and are driven by lowfrequency variations of the North Atlantic Oscillation (NAO) through changes in Labrador Sea convection (Fig. 5a). The variations in the North Atlantic thermohaline circulation appear to be predictable one to two decades ahead, as shown by a number of perfect model predictability experiments. North Atlantic SST is strongly influenced by the MOC changes and the two quantities exhibit a clear lead-lag relationship in some models, as visualized in Fig. 5b. We expect that the next few decades will be strongly influenced by such multidecadal variations, although the effects of anthropogenic climate change are likely to introduce trends. Some impact of the variations of the thermohaline circulation on the atmosphere has been demonstrated in some studies, so that useful decadal predictions with economic benefit may be possible. However, unpredictable external forcing through strong volcanic eruptions and/or anomalous solar radiation may offset the internal variations and introduce an additional source of uncertainty.

Where do we stand? A decadal predictability potential for a number of societal relevant quantities is well established. However, decadal prediction is still a challenge. We need a better understanding of the mechanisms of decadal variability. Many coupled ocean-atmosphere-sea ice models simulate decadal variability that is consistent in some respects with the available observations.

Yet, the mechanisms differ strongly from model to model. An attempt should be made to identify key regions for long-term intensive observations that will eventually help to understand the fundamental mechanisms of decadal variability in the real world. Some hotspots could be the following:

1. The Kuroshio Oyashio Extension (KOE) is a crucial region for understanding coupled feedbacks in the North Pacific. It is in this region that the ocean vigorously vents heat to the atmosphere. We therefore should ensure that future climate scientists have an adequately measured $\mathrm{KOE}$ region, including surface heat flux, subsurface thermal structure, overlying atmospheric flow, clouds, rainfall, etc. We also need to measure the basinscale wind stress forcing and the thermocline structure, as Rossby waves cross the basin and impact the KOE. Satellites and Argo will likely be adequate for measuring these large-scale features, but we need to assure the systems remain in place.
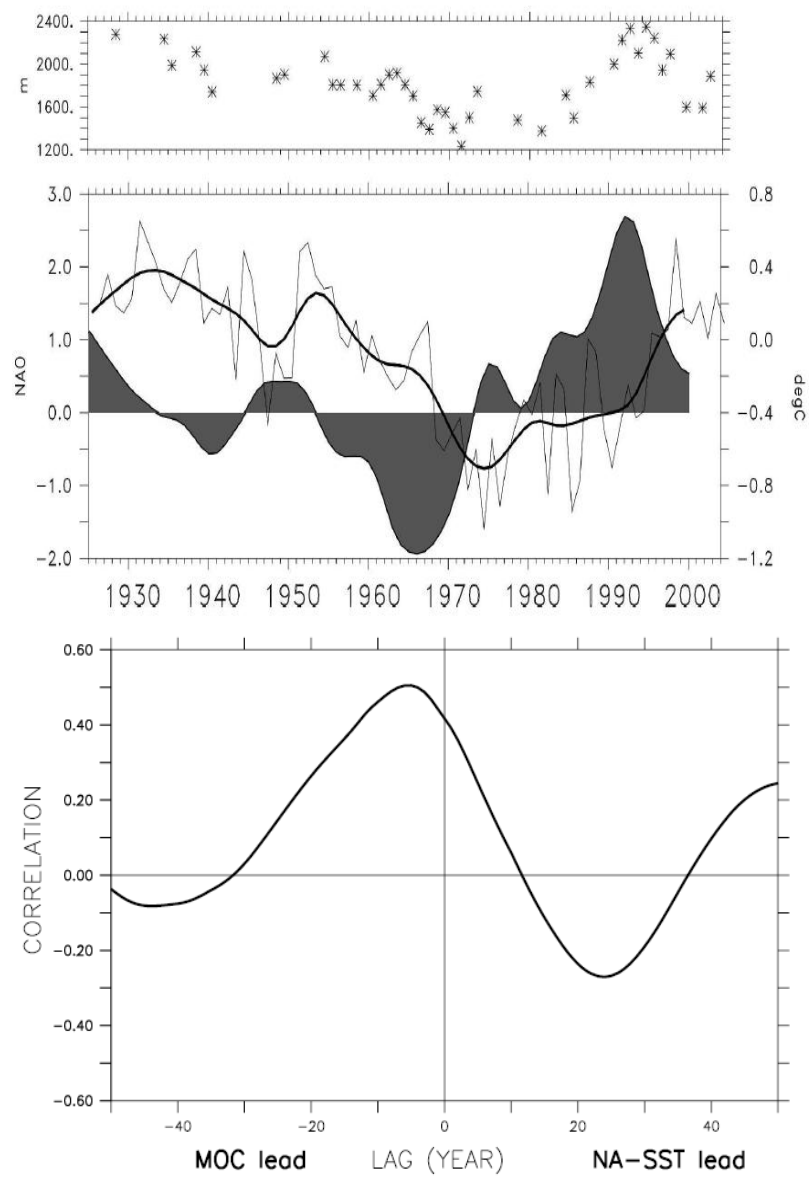

Figure 5. a) Time series of the winter [DecemberMarch (DJFM)] NAO index (shaded curve), a measure of the strength of the westerlies and heat fluxes over the North Atlantic and the Atlantic dipole SST anomaly index $\left({ }^{\circ} \mathrm{C}\right.$, black curve), and a measure of the strength of the MOC. The NAO index is smoothed with an 11-yr running mean; the dipole index is unsmoothed (thin line) and smoothed with an 11-yr running mean filter (thick line). Multidecadal changes of the MOC as indicated by the dipole index lag those of the NAO by about a decade, supporting the notion that a significant fraction of the low-frequency variability of the MOC is driven by that of the NAO. (top) Annual data of LSW thickness ( $m$ ), a measure of convection in the Labrador Sea, at ocean weather ship Bravo, defined between isopycnals $\sigma 1.5$ $=34.72-34.62$, following ([6]). b) Correlation of an MOC index with North Atlantic SST as a function of the time lag computed from a multimillennial control integration with the Kiel Climate Model (KCM). From [34]. 
2. The connections between mid-latitude and tropical ocean circulation needs to be routinely measured to understand how subduction influences the tropical circulation and concomitant atmospheric response. This is not easy to quantify or pinpoint in its regional importance, but Argo as well as the TOGA-TAO (Tropical Ocean Global Atmosphere/Tropical Atmosphere Ocean array provide some aspects of that aspect of decadal variability. A long-term program will measure indices of e. g. air-sea heat exchange, subtropical cell strength, and the low-latitude western boundary currents.

3. A similar strategy should be established for the North Atlantic MOC. We should set up long-term oceanic observation stations in the hot spots of deep oceanic mixing to be sure the long-term changes is measured. The current measurements in the Labrador Sea taken during the past 20 years are a good example. Along with those, we should be measuring the key components of atmospheric response in those regions, including the surface heat flux at sufficiently small scales to capture the response.

Furthermore, we need to improve our models. Experience gained from Numerical Weather and Seasonal Prediction shows that reduction of systematic bias helps to considerably improve forecast skill. Biases are still large in state-of-the-art climate models. Typical errors in surface air temperature, for instance, can amount up to $10^{\circ} \mathrm{C}$ in certain regions in individual models. Hotspots in this respect are, for example, the eastern tropical and subtropical oceans exhibiting a large warm and the North Atlantic and North Pacific generally suffering from a large cold bias. Likewise significant discrepancies to observations exist concerning the variability. Many models, for instance, fail to simulate a realistic El Niño/Southern Oscillation ([31]). Thus it cannot be assumed that current climate models are well suited to realize the full decadal predictability potential. Much higher resolution is one key to improve models, as shown in numerous studies. However, this requires a significant increase in the computing capacity available to the world's weather and climate centres in order to accelerate progress in improving predictions. The World Modelling Summit for Climate Prediction in 2008 recommended computing systems dedicated to climate at least a thousand times more powerful than those currently available.
Finally, we need a "suitable" climate observing system to initialize our climate models. In the past, not many sub-surface ocean observations were available, for instance, which hindered initialization and verification of decadal hindcasts. Whether the current observing system (including satellites and the ARGO fleet) is "suitable" remains to be shown. First investigations are at least encouraging. However, much more research is needed to define what "suitable" really means for decadal prediction.

\section{ACKNOWLEDGEMENTS}

The lead author would like to thank the two anonymous referees for their very helpful comments. This paper is a contribution to the Excellence Cluster "The Future Ocean".

\section{REFERENCES}

1. Alvarez-Garcia, F., Latif, M. \& Biastoch, A. (2008). On multidecadal and quasi-decadal North Atlantic variability. J. Climate, 21, 3433-3452. doi:10.1175/2007JCLI1800.1

2. Bjerknes, J. (1964). Atlantic air-sea interaction. Advances in Geophysics, Academic Press, 10, 1-82.

3. Boer, G.J. \& Lambert, S.J. (2008): Multi-model decadal potential predictability of precipitation and temperature. Geophys. Res. Lett., 35, L05706, doi:10.1029/2008GL033234

4. Collins, M. (2002). Climate predictability on interannual to decadal time scales: the initial value problem. Clim. Dynamics, 19, 671-692. doi: $10.1007 / \mathrm{s} 00382-002-0254-8$

5. Collins, M. \& Sinha, B. (2003). Predictability of decadal variations in the thermohaline circulation and climate, Geophys. Res. Lett., 30(6), 1306, doi:10.1029/2002GL016504

6. Curry, R.G., McCartney, M.S. \& Joyce, T.M. (1998). Oceanic transport of subpolar climate signals to middepth subtropical waters. Nature, 391, 575-577. doi: $10.1038 / 35356$

7. Delworth, T.L. \& Greatbatch, R.J. (2000). Multidecadal thermohaline circulation variability driven by atmospheric surface flux forcing. J. Climate, 13, 14811495.

8. Delworth, T., Manabe, S. \& Stouffer, R.J. (1993). Interdecadal variations of the thermohaline circulation in a coupled ocean-atmosphere model. J. Climate, $\mathbf{6}$, 1993-2011. 
9. Deser, C. \& Blackmon, M.L. (1993). Surface climate variations over the North Atlantic Ocean during winter). 1900-1989. J. Climate, 6, 1743-1753. doi: $10.1175 / 1520$ 0442(1993)006<1743:SCVOTN>2.0.CO;2

10. Dommenget, D. \& Latif, M. (2008). Generation of Hyper Climate Mode. Geophys. Res. Lett., 35, L02706, doi:10.1029/2007GL031087

11. Eden, C. \& Greatbatch, R.J. (2003). A damped decadal oscillation in the North Atlantic Ocean Climate System. J. Climate, 16, 4043-4060. doi:10.1175/15200442(2003)016<4043:ADDOIT>2.0.CO;2

12. Frankignoul, C. \& Reynolds, R.W. (1983). Testing a dynamical model for midlatitude sea surface temperature anomalies, J. Phys. Oceanogr., 13, 11311145 .

13. Frankignoul, C., Muller, P. \& Zorita, E. (1997). A simple model of the decadal response of the ocean to stochastic wind forcing. J. Phys. Oceanogr., 27, 15331546.

14. Frankignoul, C. \& Hasselmann, K. (1977). Stochastic climate models. Part II: application to sea surface temperature anomalies and thermocline variability, Tellus, 29, 284-305. doi: 10.1111/j.2153-3490.1977.tb00740.x

15. Griffies, S.M. \& Tziperman, E. (1995). A linear thermohaline oscillator driven by stochastic atmospheric forcing. J. Climate, 8, 2440-2453

16. Griffies, S.M. \& Bryan, K. (1997a). A predictability study of simulated North Atlantic multidecadal variability. Clim. Dynamics, 13, 459-488.

17. Griffies, S.M. \& Bryan, K. (1997b). Predictability of North Atlantic multidecadal climate variability. Science, 275, 181-184. doi:10.1126/science.275.5297.181

18. Grötzner, A., Latif, M., Timmermann, A. \& Voss, R. (1999). Interannual to decadal predictability in a coupled ocean-atmosphere general circulation model. $J$. Climate, 12, 2607-2624.

doi:10.1175/1520-

0442(1999)012<2607:ITDPIA>2.0.CO;2

19. Gu, D. \& Philander, S.G.H. (1997). Interdecadal Climate Fluctuations that depend on Exchanges between the Tropics and Extratropics, Science, 275, 805-807. doi:10.1126/science.275.5301.805

20. Hall, A. \& Manabe, S. (1997). Can Local, Linear Stochastic Theory Explain Sea Surface Temperature and Salinity Variability? Climate Dynamics, 13, $167-$ 180.

21. Hasselmann, K. (1976). Stochastic climate models. Part I: Theory. Tellus, 28, 473-485.

22. Hawkins, E. \& Sutton, R. (2009). The potential to reduce uncertainty in regional climate predictions. Bull. Am. Meteorol. Soc., 90(8),1095-1107. doi:10.1175/2009BAMS2607.1
23. Herterich K. \& Hasselmann, K. (1987). Extraction of mixed layer advection velocities, diffusion coefficients, feedback factors, and atmospheric forcing parameters from the statistical analysis of the North Pacific SST anomaly fields. J. Phys. Oceanogr., 17, 2145-2156.

24. Hurrell, J.W. (1995). Decadal trends in the NorthAtlantic-Oscillation- regional temperatures and precipitation. Science, 269, 676-679. doi:10.1126/science.269.5224.676

25. IPCC (2007). Climate Change 2007: The Physical Science Basis. Contribution of Working Group I to the Fourth Assessment Report of the Intergovernmental Panel on Climate Change, edited by S. Solomon, et al., Cambridge University Press, Cambridge, United Kingdom and New York, NY, USA.

26. Jacobs, G.A., Hurlburt, H.E., Kindle, J.C., Metzger, E.J., Mitchell, J.L., Teague, W.J. \& Wallcraft, A.J. (1994). Decade-scale trans-Pacific propagation and warming effects of an El Niño anomaly. Nature, 370, 360 - 363 doi: $10.1038 / 370360 \mathrm{a} 0$

27. Keenlyside, N., Omrani, N.E., Krüger, K., Latif, M. \& Scaife, A. (2008). Decadal predictability: How might the stratosphere be involved? SPARC Newsletter, $\mathbf{3 1}$, 23-27.

28. Latif, M. (1998). Dynamics of interdecadal variability in coupled ocean-atmosphere models. J. Climate, 11, 602624 .

29. Latif, M. (2006). On North Pacific Multidecadal Climate Variability. J. Climate, 19, 2906-2915.

30. Latif, M. \& Barnett, T.P. (1994). Causes of decadal climate variability over the North Pacific and North America. Science, 266, 634-637. doi: $10.1126 /$ science.266.5185.634

31. Latif, M. \& Keenlyside, N. (2008). El Niño/Southern Oscillation response to global warming. Proc. Nat. Ac. Sci., doi:10.1073/pnas.0710860105

32. Latif, M., Collins, M., Pohlmann, H. \& Keenlyside, N. (2006a). A review of predictability studies of the Atlantic sector climate on decadal time scales. $J$. Climate, 19, 5971-5987.

33. Latif, M., Böning, C.W., Willebrand, J., Biastoch, A., Dengg, J., Keenlyside, N., Schweckendiek, U. \& Madec, G. (2006b). Is the thermohaline circulation changing? J. Climate, 19, 4631-4637.

34. Latif, M., Park, W., Keenlyside, N. \& Ding, H. (2009). Internal and External North Atlantic Sector Variability in the Kiel Climate Model. Meteor. Zeitschrift, 18 (4), 433-443.

35. Lemke, P., Trinkl, E.W. \& Hasselmann, K. (1980). Stochastic dynamic analysis of sea ice variability. $J$. Phys. Oceanogr., 10, 2100-2120. doi:10.1175/15200485(1980)010<2100:SDAOPS >2.0.CO;2 
36. Mikolajewicz, U. \& Maier-Reimer, E. (1990). Internal secular variability in an ocean general circulation model. Climate Dynamics, 4, 145-156. doi:10.1007/BF00209518

37. Minobe, S., Kuwano-Yoshida, A., Komori, N., Xie, S.-P. \& Small, R.J. (2008). Influence of the Gulf Stream on the troposphere. Nature, 452, 206-209. doi:10.1038/nature06690

38. Palmer, T. et al. (2004). Development of a European Multi-Model Ensemble System for Seasonal to Interannual Prediction (DEMETER). Bull. Am. Meteorol. Soc., 85, 853-872. doi:10.1175/BAMS-85-6-853

39. Park, W. \& Latif, M. (2005). Ocean Dynamics and the Nature of Air-Sea Interactions over the North Atlantic. J. Climate, 18, 982-995. doi: 10.1175/JCLI-3307.1

40. Pohlmann, H., Botzet, M., Latif, M., Roesch, A., Wild, M. \& Tschuck, P. (2004). Estimating the Long-Term Predictability Potential of a coupled AOGCM. $J$. Climate, 17, 4463-4472.

41. Saravanan, R. \&. McWilliams, J.C (1998). Stochasticity and spatial resonance in interdecadal climate fluctuations. J. Climate, 10, 2299-2320.

42. Scaife, A.A., Knight, J.R., Vallis, G.K. \& Folland, C.K. (2005). A stratospheric influence on the winter NAO and North Atlantic surface climate. Geophys. Res. Lett., 32, L18715. doi:10.1029/2005GL023226

43. Schneider, N. \& Cornuelle, B. (2005). The forcing of the Pacific Decadal Oscillation. J. Climate, 18, 4355-4373.

44. Schneider, N., Miller, A.J. \& Pierce, D.W. (2002). Anatomy of North Pacific decadal variability. $J$. Climate, 15, 586-605.

45. Stommel, H.M. (1961). Thermohaline convection with two stable regimes of flow. Tellus, 13, 224-230. doi:10.1111/j.2153-3490.1961.tb00079.x

46. Sutton, R.T. \& Allen, M.R. (1997). Decadal predictability of North Atlantic sea surface temperature and climate, Nature, 388, 563-567.

47. Timmermann, A., Latif, M., Voss, R. \& Grötzner, A. (1998). Northern Hemisphere interdecadal variability: A coupled air-sea mode. J. Climate, 11, 1906-1931.

48. White, W.B. \& Peterson, R. (1996). An Antarctic circumpolar wave in surface pressure, wind, temperature, and sea ice extent. Nature, 380, 699-702. doi:10.1038/380699a0

49. Weisse, R., Mikolajewicz, U. \& Maier-Reimer, E. (1994). Decadal variability of the North Atlantic in an ocean general circulation model, J. Geophys. Res., 99(C6), 12,411-12,421. doi:10.1029/94JC00524

50. Weisse, R., Mikolajewicz, U., Sterl, A. \& Drijfhout, S.S. (1999). Stochastically forced variability in the Antarctic Circumpolar Current, J. Geophys. Res., 104(C5), 11,049-11,064. doi:10.1029/1999JC900040 